\title{
Family members' experience of a group-based multi-professional educational programme about chronic heart failure
}

\author{
Caroline Löfvenmark ${ }^{* 1,2}$, Ewa Billing ${ }^{3}$, Magnus Edner ${ }^{4}$, Anne-Cathrine Mattiasson ${ }^{5}$ \\ ${ }^{1}$ Karolinska Institutet, Department of Clinical Sciences, Danderyd Hospital, Division of cardiovascular medicine, Stockholm, \\ Sweden \\ ${ }^{2}$ Sophiahemmet University, Stockholm, Sweden \\ ${ }^{3}$ Department of Medical Sciences, Uppsala University, Uppsala, Sweden \\ ${ }^{4}$ Karolinska Institutet, Department of Medicine, Cardiology research unit, Karolinska University Hospital, Stockholm, Sweden \\ ${ }^{5}$ Karolinska Institutet, Department of Neurobiology, Care Sciences and Society, Division of Nursing, Huddinge, Sweden
}

Received: December 23, 2014

Accepted: March 3, 2015

Online Published: March 11, 2015

DOI: $10.5430 /$ cns.v3n3p9

URL: http://dx.doi.org/10.5430/cns.v3n3p9

\begin{abstract}
Objective: The aim was to evaluate how family members of persons with chronic heart failure (CHF) experienced a group-based multi-professional educational programme.

Methods: Family members who participated in an educational programme filled in an evaluation form directly after completing the programme $(n=53)$. One year after the completed programme family members $(n=11)$ who participated in 5-6 of six sessions were interviewed about their experience. The interviews were analysed by qualitative content analysis.

Results: The evaluation form showed that most family members reported satisfaction with session structure and content, but a majority would have preferred to share the education together with the ill person. Interview findings are presented in three categories and eight subcategories identified through the analysis. Results showed that family members' increased knowledge about heart failure and thereby attained a greater understanding of the ill person's situation with an increased tolerance. Furthermore the family members acquired a better self-confidence and became a resource for the ill person and they described that they were more actively involved in the ill person's self-care. Family members experienced it positive to meet others in the same situation. They also gained an insight into the importance of taking care of their own health.

Conclusions: The educational programme produced valuable knowledge and understanding about heart failure among family members. With this newly acquired knowledge, family members had the possibility of working out appropriate support for the ill person. Being part of a group with others in the same situation was a positive experience.
\end{abstract}

Key Words: Heart failure, Multi-professional, Educational programme, Family members

\section{INTRODUCTION}

When a person has a serious illness, such as chronic heart failure (CHF), studies have shown that family members are affected physically, emotionally, and socially. ${ }^{[1-4]} \mathrm{CHF}$ is a common syndrome with various underlying causes. ${ }^{[5]}$ The most common symptoms of patients with CHF experience are breathlessness, lack of energy, tiredness, and fatigue. ${ }^{[5,6]}$ Despite modern treatment of CHF, the prognosis is poor. ${ }^{[7]}$ Daily life is limited for family members due to the patient's illness, ${ }^{[2,3,8]}$ by daily medication the ill person has to take ${ }^{[3]}$

*Correspondence: Caroline Löfvenmark; Email: caroline.lofvenmark@shh.se; Address: Sophiahemmet University, Stockholm, Sweden. 
and by the patient's physical limitations caused by $\mathrm{CHF}^{[4]}$

Family members of persons with $\mathrm{CHF}$ often provide care such as assisting with medication, observing symptoms, and providing emotional support. ${ }^{[2,8,9]}$ They sometimes need to make decision about seeking care for the ill person, ${ }^{[10]}$ although it is often difficult for spouses to get information about the illness from health care professionals. ${ }^{[2-4]}$ Spouses have experienced lack of recognition as a resource for the patient and feel that they are invisible to the health care professionals. ${ }^{[4]}$ Lacking of informations has been described as stressful, ${ }^{[11]}$ creating frustration, ${ }^{[2]}$ and worry. ${ }^{[4]}$ Receiving adequate informations and being included in the patient's care are important factors for family members to support the patient. $^{[2,3]}$

Discussions with someone in the same situation are described as helpful, because those individuals have a genuine understanding of the situation. ${ }^{[3]}$ Group-based education, including group sessions, provides opportunities to share experiences and to receive practical and emotional support from each other. ${ }^{[12,13]}$ Educational interventions aimed at improving knowledge and support systems for spouses of patients with different diagnoses have previously shown positive results, ${ }^{[14-18]}$ such as increased disease-related knowledge, ${ }^{[17]}$ reduced distress ${ }^{[18]}$ and improved family function. ${ }^{[14]}$

In a care program for both patients with $\mathrm{CHF}$ and their partners, the patients improved their level of perceived control during a period of three months, but their partners' level of perceived control remained unchanged. ${ }^{[19]}$ Dunbar and colleagues $^{[15]}$ found that the family member's knowledge about CHF increased after participating in an educational programme. A qualitative evaluation of a nursing intervention for family members of patients with $\mathrm{CHF}$ showed that improved disease-related knowledge decreased family members' worries and that they became more understanding of their relative who suffered from $\mathrm{CHF}^{[20]}$

Only a few studies have systematically evaluated educational programmes aimed at family members of persons with CHF. ${ }^{[16]}$ These educational programmes have been given to both the family member and the patient. ${ }^{[15,19,20]}$ To our knowledge, no previous educational programme has been offered exclusively to only family members of patients with CHF. This paper focuses on a multi-professional educational programme offered to family members of persons with $\mathrm{CHF}$, evaluated with an evaluation form and with individual interviews as complements to each other. The programme has been previously evaluated by quantitative methods. ${ }^{[21,22]}$ Analysis of heart failure knowledge showed a statistic significant increased knowledge between first (baseline) and second (after six months) assessment (13.5 \pm 3.0 vs. $16.0 \pm$
$1.9, p<.001$ ), but not between second and third (after twelve months) assessment $(16.0 \pm 1.9 v s .16 .5 \pm 1.3, p=.055) .{ }^{[21]}$ The programme did not affect family members' quality of life, anxiety and depression, ${ }^{[22]}$ nor did it affect the patients' health care utilization. ${ }^{[21]}$

Definition of family members in this study was someone the patient was living with or otherwise someone else the patient chose as a family member. The aim of the study was to evaluate how family members of persons with chronic heart failure experienced a group-based multi-professional educational programme.

\section{Methods}

\subsection{Multi-professional educational programme}

The educational programme has been presented elsewhere, ${ }^{[21,22]}$ which is why it is just briefly described below. Sixty-five family members of patients with CHF were invited to participate in a multi-professional educational programme about CHF whereof 53 family members completed the programme. The multi-professional educational programme about CHF included sessions in: medical aspects (cardiologist), self-care (specialist nurse in CHF), nutrition (dietician), physical activities (physiotherapist), and psychological aspects (social worker). Before each session a letter of reminder was sent to the participants. Each session included information about the actual theme by one of the professionals, and there was always time for questions, discussion, and reflection. The participants met for six sessions, two hours/session, during a period of six months, in groups of eight family members. The sessions were mostly at Mondays between $5 \mathrm{pm}$ and $7 \mathrm{pm}$.

The educational programme was developed based on the recommended topics in patient education from the European Society of Cardiology guidelines. ${ }^{[23]}$ The topics are related to different professions in health care.

\subsection{Data collection}

Data collection was done by anonymous evaluation forms directly after the last session and with individual interviews with family members one year after they completed the programme.

\subsubsection{Evaluation form directly after completing the pro- gramme}

An evaluation form, developed for this study, was filled in directly after they completed the multi-professional educational programme. The evaluation form was given to the family members at the last session, and they were asked to fill out the form, anonymously, and to send it back within two weeks. 
The evaluation form consisted of 21 questions with fixed response alternatives, such as excellent, good, rather good, bad, and very bad. The following aspects were included: structure of the programme ( 6 questions), content of the programme (6 questions), participant's view on attending the programme in a group with or without the ill person (4 questions), expectations of the programme (3 questions), and usefulness (2 questions).

\subsubsection{Individual interviews one year after programme completion}

Inclusion criteria were family members who had participated in the multi-professional educational programme five or six sessions out of the possible six sessions. Family members were consecutively asked for participation in the study. Written information about the study was sent to the family members one year after programme completion. One week later the first author contacted the family members by telephone for oral information and to ask about participation. Eleven family members were included, ten women and one man. The first author agreed on a time and place for the interviews with the participants, striving to meet the participants' wishes. Six of the interviews took place at a meeting room at the hospital, four interviews were carried out in a room at the first author's place of work, and one interview was performed at the respondent's home.

The semi-structured qualitative interviews were carried out one year after completing the programme. An interview guide was used ${ }^{[24]}$ comprising the following aspects:

(1) Family members' knowledge in relation to the different themes in the educational programme.

(2) Whether family members' own lifestyle in any way was affected by attending the programme.

(3) Whether in any way new questions emerged for the family members by attending the programme.

(4) Whether attending the programme in any way created fear or insecurity.

Each interview was commenced by asking "If you look back on the educational programme, can you please tell me about your experience and the knowledge you have gained and used by attending the programme". This question gave the participants the opportunity to speak freely and in their own words about their experiences.

The interviews lasted between 40 and 75 minutes and were tape-recorded with the participants' permission. One pilot interview was performed with the same inclusion criteria; the interview was considered to be of a good quality and was, therefore, included in the study.

Published by Sciedu Press

\subsection{Data analysis}

\subsubsection{Evaluation form}

The evaluation forms are presented with numbers and per cent. The data were analysed with SPSS for Windows version 18 (Chicago, Illinois).

\subsubsection{Individual interviews}

The interviews were analysed using qualitative content analysis with an inductive design. ${ }^{[24]}$ The analysis was conducted in the following way: The interviews were listened through and transcribed verbatim. After transcription, the tapes were listened through simultaneously while reading the transcript. The transcripts were found to be accurate. The interviews were then read several times to comprehend a sense of wholeness. Coding of two interviews where family members expressed their experiences about interview topics was done by two of the authors (CL and A-C M) independently. The coded text was discussed and the coding modified. Thereafter the first author continued the analytic process, i.e. identifying codes, which were modified during the course of the analysis. The codes were sorted into sub-categories and further into categories. The programme Open Code $(2007)^{[25]}$ was used to structure the data.

\subsection{Ethical issues and approval}

All participants received an information letter ensuring confidentiality, voluntary participation, and the right to withdraw from participation at any time. The study has been approved by the Regional Ethical Review Board, Stockholm, Dnr 2006/801-32.

\section{RESUlTS}

\subsection{Self-reported evaluation directly after completed programme}

The self-reported evaluation was given to 55 of the participants who had attended the educational programme at least one time, and altogether $53(96 \%)$ participants filled out the evaluation form. The participants in the educational programme were between ages 38 and 88 years, mean age 64 ( \pm 13) years. Thirty-seven of the family members were living together with the ill person, 21 were children of the ill person, two persons were close friends, and five were relatives of the ill person. The median attendance rate was five sessions.

\subsubsection{Structure of the programme}

Most of the family members were satisfied with the number ( $n=46)$ and length $(n=48)$ of the sessions. Starting time at $5 \mathrm{pm}$ was considered as good by the majority $(n=46)$, as well as the day of the week $(n=52)$. Most of the family members $(n=44)$ were satisfied with the number of participants in the groups. The information before the sessions was 
considered sufficient by a majority of the participants $(n=$ 49).

\subsubsection{Content of the programme}

Most of the family members experienced the programme as a whole as excellent $(n=27)$ or good $(n=20)$. The different meetings were mostly considered excellent or good, but a few participants were less satisfied.

\subsubsection{Family members' views about attending the pro- gramme in a group with or without the ill person with heart failure}

To attend the education together with other family members in a group was considered to be excellent $(n=34)$ or good $(n=15)$ by the participants. Most of the family members $(n$ $=36$ ) would have preferred to attend the education together with the ill person. Of those 26 family members would have preferred to have it in a group, and 25 of the family members would have liked the ill person to be present in this educational programme or as a complement.

\subsubsection{Expectations and usefulness of the programme}

The programme met most of the family members' expectations $(n=44)$, most of them $(n=41)$ did not miss anything nor did they wish for anything more. However, four participants would have liked time to discuss private specific needs that the ill person had and their role as informal caregiver. The majority $(n=46)$ answered that they could use what they had learned in their daily life, and most of them $(n=50)$ had discussed what they learned with the ill person.

\subsection{Experience of the programme from the interviews}

The family members that were interviewed were between ages 38 and 80 years, with a median age of 58 years. Four of the family members were living together with the ill person, five were children of the ill person, one person was a sister, and one was a relative that the ill person had chosen as family member. The findings of the interviews are presented in eight subcategories and three categories (see Table 1).

Table 1. Categories and subcategories created from the content analysis

\begin{tabular}{|c|c|}
\hline Subcategories & Categories \\
\hline Understanding heart failure and its symptoms & \\
\hline $\begin{array}{l}\text { Increasing understanding and tolerance for the patient } \\
\text { Creating uncertainty }\end{array}$ & Making the disease comprehensible \\
\hline Creating self-confidence versus worries & \\
\hline $\begin{array}{l}\text { Creating security and communication } \\
\text { Contributing and sharing self-care activities }\end{array}$ & Increasing involvement \\
\hline $\begin{array}{l}\text { Sharing individual experiences } \\
\text { Living healthier }\end{array}$ & Positive changes in family member' own lives \\
\hline
\end{tabular}

\subsubsection{Making the disease comprehensible}

Understanding heart failure and its symptoms Family members described gaining an overall view of CHF and that they had now understood that this is a serious and lifelong disease. They mentioned that they had heard about CHF before the meetings, but had previously not really understood what it was, as a family member expressed it: "the heart failed". Family members described several signs and symptoms that they had seen previously, which now had been confirmed as a clinical picture of CHF. They found that this knowledge was important for their own understanding of the disease.

Everything has fallen into place today ... that this is connected to this, which is connected to this, which is connected to that ....

Increasing understanding and tolerance for the patient Family members had acquired a better understanding of the ill person and his/her condition, both in medical and psycho- logical aspects. They expressed a new understanding that the tiredness the ill person experienced was related to $\mathrm{CHF}$, and family members therefore became more tolerant. They also became more understanding about the ill person's need to rest when taking a walk and that signs of confusion could be due to lack of circulation and not necessarily the beginning of a dementia disease. They said they had learned about the changeable nature of the disease, where the ill person feels strong and alert one day, and is totally exhausted the next day. Because of this, family members gained a better understanding of the importance of the ill person's need to rest the day before special occasions. They also understood the importance of planning so that the ill person felt that he/she had enough time and did not feel stressed, and the family member became less irritated at the fact that it takes time, for example when shopping for food. Thereby the situation improved for both parts.

On the whole, I believe that this educational programme has increased my understanding for my 
mother and her disease, her way of living and being, and how she does things, it has definitely increased my understanding for why, some days, she doesn't want to do anything

Creating uncertainty The signs and symptoms experienced by the ill person were not isolated events but intertwined with other aspects related to effects of other diseases and/or old age. Therefore, the family members' increased knowledge about $\mathrm{CHF}$ sometimes made it difficult to distinguish between the symptoms of $\mathrm{CHF}$ and those symptoms related to the natural aging process. They expressed that it could be difficult to understand if the symptoms were signs of worsening $\mathrm{CHF}$, or were caused by other circumstances that affected the ill person's physical condition, such as for example, after an operation or from a common cold. This created uncertainty and difficulties in deciding when and if it was time to seek health care or what to do. They questioned why they had not received this information during the ill person's hospitalisation.

He has had a very annoying cold which entailed a lot of coughing ... he's been coughing a lot during the night, then you realize that coughing is also one of those symptoms, but as I understand it, it's a different type of cough, it was a dry kind of cough the last time.

Creating self-confidence versus worries The family members said that most of the information discussed in the programme was not troublesome to hear about. On the contrary, it created a feeling of self-confidence in everyday life to know more about what had happened and what caused the $\mathrm{CHF}$ and also some preparedness of how to handle it. They also described whether they felt confident in their role; this feeling of confidence enabled the ill person to feel more secure.

Understanding the seriousness of the disease was expressed as the most burdensome aspect to learn, and the increased knowledge created some worries, which in turn led to that the family members contacted the ill person more often than before. Hearing about other ill person's individual course of CHF was expressed as both positive and negative, the positive aspect was that they now knew more about what to expect eventually and therefor were more prepared for the future. Actually it is better to know ... you have had enough of worries at this stage.

\subsubsection{Increasing involvement}

Creating security and communication Family members described feeling more knowledgeable and confident and had shared their extended knowledge with the ill person. They felt that he/she was listening and paid more attention to their opinions and advice. They described how they felt they had become a resource for others when sharing their knowledge both with family and friends, discussing symptoms, drug therapy, and the seriousness of the illness. With their new knowledge, family members also expressed increased communication; they became someone the ill person could turn to and discuss different issues with. To have someone to lean on increased the feeling of security for the ill person.

I believe that Dad has felt a huge sense of security, as there is now someone close by who actually may know more than he does ... or know more, but he can juggle these questions with, someone who is calm and has time.

Contributing and sharing self-care activities Family members described they were more actively involved in the ill person's self-care than they were before. They said that they understood the importance of being observant and checking the leg oedema and reminding the ill person to be observant of their own weight. They knew it was possible to increase diuretics in the case of worsening $\mathrm{CHF}$ or sometimes changing the time to take the diuretic without needing to get in contact with a health care provider. They said that they now knew how to ease the thirst by sucking on ice or taking tablets that increased the saliva. Family members had understood that it was important that the ill person did not drink too much fluid, and encouraged the ill person to try to have control over his/her fluid intake by measuring the fluid. Their expanding consciousness about the importance of self-care motivated them to support the ill person to take walks; and if the ill person was unable to walk, they encouraged him/her to move a little or to take part in some housework. If the ill person had a loss of appetite, family members understood it could be an effect of the disease and tried to encourage his/her to eat anyway.

That you should sit and do leg exercises ... I thought this was good, I was able to go home and tell my Mum this is what you should do.

\subsubsection{Positive changes in family members' own lives}

Sharing individual experiences To be part of a group and meeting and talking with others in the same situation was a positive experience, and it created a feeling of being someone and of being seen. They expressed it as somehow a relief to meet with others to discuss difficulties and worries and thereby realize they were not alone in their situation. Family members experienced it as a give and take situation, and said that they ventilated issues that felt troublesome but also 
learned how to handle different situations. They said it was valuable that through their shared experiences, they understood how others felt and that it was acceptable to feel and react the way they did sometimes, without any blame. Family members said that the best part of taking part in the groups was to have the opportunity to exchange their experiences with others who understood and shared similar experiences. The opportunity to talk freely about their situation without the ill person present was considered as positive. Family members expressed that they would have liked a possibility to meet in the future, and to have follow-up meetings. ... To exchange experiences... well, you discover that it's not only my family....

Living healthier Family members described that they acquired a personal knowledge which made them more aware and conscious of the importance of considering their own health and in taking care of themselves and that they now better understood their own needs. This was expressed by being more active and exercising, taking walks, and eating healthier. Family members said that they tried to allow themselves time for rest and recreation and time to do pleasant and cheerful things sometimes.

I have actually thought about this during the past year, but I am uncertain about how much it has influenced me ... but I know one thing, I deliberately try to find more time for recovery.

\section{Discussion}

This study focused on family members' experience of participating in an educational programme which was evaluated by two different methods in parallel: an evaluation form and individual interviews, altogether to gain a deeper understanding. ${ }^{[26]}$ The interviews allowed family members to speak freely about their experiences.

Our findings showed that the educational programme produced valuable knowledge and understanding with respect to CHF and its symptoms, and because they had that knowledge family members gained a greater understanding and could support the ill person in an appropriate way. Results from the evaluation form showed that several family members would have liked the ill person to join the programme or parts of it

To attain knowledge and information and to come together and exchange personal experiences with other family members of persons with CHF was valuable and meaningful in many ways, and supported them in accepting the feelings that they sometimes had without feeling guilty.

Findings in the present study, both in the evaluation form and the individual interviews, showed that knowledge increased in family members through participation in the educational programmes, which has been confirmed by previous studies. ${ }^{[15,17,20,21]}$ Our results also showed that the acquired knowledge was useful in daily life for both family members and the ill person. Duhamel and colleagues ${ }^{[20]}$ also found that both the spouse and the ill person learned how to deal with the disease better. The increased insight into CHF and its effect on the ill person provided the family members in the present study with a better understanding and tolerance in different situations for the person with CHF. This is in line with the findings by Duhamel and colleauges ${ }^{[20]}$ where the spouses expressed that they became more understanding of the ill person. The acquired knowledge created security because family members were better prepared to handle different situations associated with CHF. Findings by Duhamel and colleagues ${ }^{[20]}$ confirmed that family members felt more secure with increased knowledge. However, in this study we found that increased knowledge of CHF also created worries for the family members. The main cause of worry was the insight into the seriousness of CHF and the fact that it is a lifelong disease and therefore there is uncertainty about the future. But they still mentioned that it was better to have proper information, and family members said that they already had worries for the ill person. On the contrary not receiving information has been shown previously to create worries. ${ }^{[2,3]}$ This implies the importance of tailoring to actually meet the individual family members' needs.

The findings showed that there were family members that would have preferred to share the education together with the ill person. Earlier studies investigating the importance of education about disease-specific knowledge for family members has directed the education mostly to both the ill person and their family member, ${ }^{[14,15,20]}$ but an educational programme for family members of stroke patients was directed only to the family members. ${ }^{[17,27]}$ They did however not evaluate whether the participants would have preferred to have the education together with the person who had the stroke or not. The basic idea with the present programme was that it is important for family members to have the opportunity to express themselves and their experiences without the presence of the ill person, so that they could talk about their worries and discuss different issues openly and freely. There were family members who expressed appreciation for the possibility to be able to talk without the ill person present; they would not have been able to speak so freely if the person with CHF participated. It might have been good to invite the ill person to some of the sessions and have discussions based on their questions and experiences as well as providing them with a possibility to meet other persons with heart failure and share individual experiences. 
Overall, the participants considered the structure of the programme to be good. However, there were family members who would have liked the opportunity to have private discussions about their own situation and the special needs of their ill relative. This was also found in the study by Franzén and colleagues, ${ }^{[17]}$ where family members wanted to have private talks with a nurse. There were also family members in the present study who wished to talk about their role as an informal caregiver. To give general information about the disease is of great value, but family members still need to be able to talk about their own situations. It might have been of value to include a private session in the educational programme.

Another valuable aspect of being offered this educational programme was that it created a feeling of becoming someone and being seen. This means that probably some of their needs had earlier been ignored by health care professionals similar to findings reported by Phil and colleagues ${ }^{[4]}$ when spouses had feelings of being invisible to the health care professionals. The authors stated that family members are important for the person with heart failure, but they need guidance and support from health care professionals to gain skills to be supportive for the ill person in his/her disease.

\section{Methodological considerations}

In the written evaluation of the educational programme 91 percent of the family members that participated filled out the evaluation form which should be considered a high answering frequency. The questions were directly connected to evaluating the structure and the content of the programme. In the interview section in this study, eleven family members participated, which can be seen as a rather small sample size. There are no precise rules for sample size in qualitative design; the goal is rather to gain rich information that fits the purpose of the study ${ }^{[24]}$ and when data seems to be repetitive, i.e. saturation has been achieved. ${ }^{[26]}$ After ten interviews data seemed to be repetitive and one further interview were conducted to validate the collected data.

The interviews were carried out one year after completion of the programme about family members' experience of participating in the programme. This might have caused bias since other circumstance might have influenced family members' experiences. The aim of the interviews was, however, to evaluate whether the programme influenced family member during long-term. Family members accepted to participate one year after completion of the programme and gave a rich material of their experience. The location for the interviews was decided in agreement between the interviewer and the participants, with an aspiration to meet family members' wishes. ${ }^{[26]}$ The participants could choose to meet at the hos-

Published by Sciedu Press pital, in a room at the first author's place of work or in their own home. Most of the interviews were carried out at the hospital or the first author's place of work. The interviewed persons were all familiar with the interviewer because they had attended the educational sessions for which the interviewer was responsible and had a function as coordinator. This might have influenced the results, in that the participants may have been less prone to criticise the programme. The interviewer asked if there was any information that could have been omitted or that they felt was missing. On the other hand the participants could have felt more comfortable meeting someone whom they had previously met and therefore felt free to express their thoughts.

To validate the interview transcription and facilitate the analysis, all interviews were transcribed verbatim. After transcription, the tapes were listened through while simultaneously reading the transcript. ${ }^{[24]}$ To increase the credibility of the analysis two of the authors read several interviews independently and discussed coding leading to consensus. ${ }^{[24,28]}$ When presenting findings the authors used representative quotations from the transcribed text to increase the credibility. ${ }^{[28]}$ Certain linguistic and grammatical revisions have been made to the quotations because the interviews were translated from Swedish into English and when the spoken language is put directly in to writing, it may be difficult to understand. ${ }^{[29]}$

To be interviewed could be seen as intrusive as participants were asked to share thoughts and experiences. ${ }^{[24]}$ However, the interviews did not, in general, deal with highly personal matters. The participants were told that they could contact the interviewer if they had any questions or thoughts.

\section{Conclusion}

The educational programme produced valuable knowledge and understanding about chronic heart failure for family members. The acquired knowledge gave family members the possibility of giving appropriate support for the ill person even one year after completion of the education programme. A multidisciplinary approach to the education of family members is important, in that each of the professions has an important role to play in providing knowledge of the disease. Time and space for exchanging personal experiences with others in the same situation should be included in the structure of such a programme.

More studies are needed to provide a solid scientific foundation for designs for future educational programmes, i.e. what structure and content should be included and whether this should be provided together or without the ill person present, or in combination. 


\section{ACKNOWLEDGEMENTS}

We want to thank all the family members who participated and made their contribution to the study. Financial support was given by grants from Sophiahemmet University and through the regional agreement on medical training and clinical research (ALF) between Stockholm County Council and Karolinska Institutet.

\section{REFERENCES}

[1] Brannstrom M, Ekman I, Boman K, et al. Being a close relative of a person with severe, chronic heart failure in palliative advanced home care - a comfort but also a strain. Scand J Caring Sci. 2007; 21(3): 338-44. PMID:17727546.

[2] Imes CC, Dougherty CM, Pyper G, et al. Descriptive study of partners' experiences of living with severe heart failure. Heart Lung. 2011; 40(3): 208-16

[3] Martensson J, Dracup K, Fridlund B. Decisive situations influencing spouses' support of patients with heart failure: a critical incident technique analysis. Heart Lung. 2001; 30(5): 341-50. PMID:11604976. http://dx.doi.org/10.1067/mhl.2001.116245

[4] Pihl E, Fridlund B, Martensson J. Spouses' experiences of impact on daily life regarding physical limitations in the loved one with heart failure: a phenomenographic analysis. Can J Cardiovasc Nurs. 2010 20(3): 9-17.

[5] McMurray JJ, Adamopoulos S, Anker SD, et al. ESC guidelines for the diagnosis and treatment of acute and chronic heart failure 2012: The Task Force for the Diagnosis and Treatment of Acute and Chronic Heart Failure 2012 of the European Society of Cardiology. Developed in collaboration with the Heart Failure Association (HFA) of the ESC. Eur J Heart Fail. 2012; 14(8): 803-69.

[6] Zambroski CH, Moser DK, Bhat G, et al. Impact of symptom prevalence and symptom burden on quality of life in patients with heart failure. Eur J Cardiovasc Nurs. 2005; 4(3): 198-206.

[7] Cowie MR, Zaphiriou A. Management of chronic heart failure. BMJ. 2002; 325(7361): 422-5. PMID:12193359. http://dx.doi.org/1 $0.1136 / \mathrm{bmj} .325 .7361 .422$

[8] Luttik ML, Jaarsma T, Veeger N, et al. Caregiver burden in partners of Heart Failure patients; limited influence of disease severity. Eur J Heart Fail. 2007a; 9(6-7): 695-701.

[9] Pressler SJ, Gradus-Pizlo I, Chubinski SD, et al. Family caregiver outcomes in heart failure. Am J Crit Care. 2009; 18(2): 149-59.

[10] Patel H, Shafazand M, Schaufelberger M, et al. Reasons for seeking acute care in chronic heart failure. Eur J Heart Fail. 2007; 9(6-7): 702-8.

[11] Stewart M, Davidson K, Meade D, et al. Myocardial infarction: survivors' and spouses' stress, coping, and support. J Adv Nurs. 2000; 31(6): 1351-60. PMID:10849146. http://dx.doi.org/10.1046 /j.1365-2648.2000.01454.x

[12] Barlow JH, Bancroft GV, Turner AP. Self-management training for people with chronic disease: a shared learning experience. J Health Psychol. 2005; 10(6): 863-72.

[13] Burell G. Group psychoterapy in project new life: treatment of coronary-prone behaviors for patients who have had coronary artery bypass graft surgery. Heart \& Mind: The emergence of Cardiac Psychology. (e-book) 1st ed ed. Washington D.C.: American Psychological Association; 1996. 291-310p.

[14] Clark MS, Rubenach S, Winsor A. A randomized controlled trial of an education and counselling intervention for families after stroke. Clin Rehabil. 2003; 17(7): 703-12.
[15] Dunbar SB, Clark PC, Deaton C, et al. Family education and support interventions in heart failure - A pilot study. Nursing Research. 2005; 54(3): 158-66.

[16] Dunbar SB, Clark PC, Quinn C, et al. Family influences on heart failure self-care and outcomes. Journal of Cardiovascular Nursing. 2008; 23(3): 258-65.

[17] Franzen-Dahlin A, Larson J, Murray V, et al. A randomized controlled trial evaluating the effect of a support and education programme for spouses of people affected by stroke. Clin Rehabil. 2008; 22(8): 722-30.

[18] Given B, Sherwood PR. Family care for the older person with cancer. Semin Oncol Nurs. 2006; 22(1): 4350.

[19] Agren S, Evangelista LS, Hjelm C, et al. Dyads affected by chronic heart failure: a randomized study evaluating effects of education and psychosocial support to patients with heart failure and their partners. J Card Fail. 2012; 18(5): 359-66.

[20] Duhamel F, Dupuis F, Reidy M, et al. A qualitative evaluation of a family nursing intervention. Clin Nurse Spec. 2007; 21(1): 43-9.

[21] Lofvenmark C, Karlsson MR, Edner M, et al. A group-based multi-professional education programme for family members of patients with chronic heart failure: effects on knowledge and patients' health care utilization. Patient Educ Couns. 2011; 85(2): e1628. PMID:21050694. http://dx.doi.org/10.1016/j.pec. 201 0.09 .026

[22] Lofvenmark C, Saboonchi F, Edner M, et al. Evaluation of an educational programme for family members of patients living with heart failure: a randomised controlled trial. J Clin Nurs. 2013; 22(1-2): 115-26. PMID:22946864. http://dx.doi.org/10.1111/j.136 5-2702.2012.04201.x

[23] Dickstein K, Cohen-Solal A, Filippatos G, et al. ESC Guidelines for the diagnosis and treatment of acute and chronic heart failure 2008: the Task Force for the Diagnosis and Treatment of Acute and Chronic Heart Failure 2008 of the European Society of Cardiology. Developed in collaboration with the Heart Failure Association of the ESC (HFA) and endorsed by the European Society of Intensive Care Medicine (ESICM). Eur Heart J. 2008; 29(19): 2388-442.

[24] Patton MQ. Qualitative research \& evaluation methods. Third edition ed. Thousand Oaks: Sage Publications; 2002. 124 p.

[25] Epidemiology OCUa. Version 3.4 ed. 2007.

[26] Polit DF, Beck CT. Nursing research: Generating and assessing evidence for nursing practice. Ninth ed. Philadelphia: Pennsylvania Wolters Kluwer Health, Lippincott Williams \& Wilkins; 2012.

[27] Larson J, Franzen-Dahlin A, Billing E, et al. The impact of a nurseled support and education programme for spouses of stroke patients: a randomized controlled trial. J Clin Nurs. 2005; 14(8): 995-1003. PMID:16102151. http://dx.doi.org/10.1111/j.1365-2702. $2005.01206 . x$

[28] Graneheim UH, Lundman B. Qualitative content analysis in nursing research: concepts, procedures and measures to achieve trustworthiness. Nurse Educ Today. 2004; 24(2): 105-12. http://dx.doi.o $\mathrm{rg} / 10.1016 / \mathrm{j}$. nedt. 2003.10 .001

[29] Kvale SB Svend. Interviews: learning the craft of qualitative research interviewing. Second editition ed. Thousand Oaks: California Sage; 2009.

ISSN 2324-7940 E-ISSN 2324-7959 